\title{
A Brunhes-Matuyama polarity transition record from anoxic sediments in the South Atlantic (Ocean Drilling Program Hole 1082C)
}

\author{
Toshitsugu Yamazaki and Hirokuni Oda \\ Geological Survey of Japan, National Institute of Advanced Industrial Science and Technology, 1-1-1 Higashi, Tsukuba 305-8567, Japan
}

(Received February 8, 2000; Revised May 1, 2001; Accepted May 15, 2001)

\begin{abstract}
A paleomagnetic study was performed on Hole 1082C sediment cores taken during the Ocean Drilling Program (ODP) Leg 175 in the South Atlantic in order to obtain a high-resolution Brunhes-Matuyama (B/M) polarity transition record. An average sedimentation rate was as high as $10 \mathrm{~cm} / \mathrm{kyr}$. The cores consist of strongly anoxic sediments, which is common for the areas of large material supply. Anoxic sediments, which are geochemically quite active, were considered to be unsuitable for studies on detailed behavior of the geomagnetic field such as polarity transitions. For global site distribution, however, it is necessary to make efforts to retrieve paleomagnetic records from such sediments. A continuous record of directional changes around the transition was obtained from U-channel samples after cleaning by stepwise alternating-field (AF) demagnetization. Consistency of the record was checked using discrete samples taken from the other half of the cores. The coring-induced magnetic overprint of radial-inward direction, which has often been reported from ODP piston-cores, was negligibly small in our cores. Relative paleointensity variation was estimated from remanent intensities of the discrete samples normalized by artificial remanences. Our record shows following features of the B/M transition similar to those already reported by previous studies. A zone of large directional fluctuations with low paleointensities occurs just before the main transition (788 to $795 \mathrm{ka}$ based on the oxygen-isotope stratigraphy), which would correspond to the "precursor" of Hartl and Tauxe (1996). The virtual geomagnetic poles (VGPs) at the precursor lie along the so-called preferred longitudinal bands over the north-south Americas and Australia-east Asia. After the main transition from the reversed to normal polarity, VGPs stayed in the middle-to-high latitudes over the North America with an intermediate paleointensity for about $5 \mathrm{kyrs}$, and then moved in the vicinity of the North Pole with full recovery of intensity. Such behavior was reported by Oda et al. (2000). These similarities suggest that the anoxic sediments at Site 1082 could record the behavior of the geomagnetic field rather faithfully, although the remanence may be of chemical origin.
\end{abstract}

\section{Introduction}

Polarity reversal is the most spectacular among the geomagnetic field variations. For understanding better the mechanism of the geodynamo, it is important to document detailed behavior of the geomagnetic field during polarity reversals. Recent progress in numerical modeling of the geodynamo, which has succeeded to simulate a polarity reversal (Glatzmaier and Roberts, 1995), urges paleomagnetists to produce high resolution paleomagnetic records of polarity reversals for testing the models. However, a reversal completes in a geologically very short period of time, which makes it difficult to be recorded at evenly distributed sites on the globe with high enough resolution.

Based on virtual geomagnetic pole (VGP) positions during polarity transitions recorded in marine sediments or sedimentary rocks, it has been suggested that VGPs are tend to be confined to two antipodal longitudinal bands; one is over the eastern Asia and Australia and another along Americas (Clement, 1991; Laj et al., 1991), and these bands coincide with regions of fast $p$-wave propagation in the lowest man-

Copy right (C) The Society of Geomagnetism and Earth, Planetary and Space Sciences (SGEPSS); The Seismological Society of Japan; The Volcanological Society of Japan; The Geodetic Society of Japan; The Japanese Society for Planetary Sciences. tle (Laj et al., 1991). The "preferred path" hypothesis has been debated intensively since then; for example, statistical significance including the dependence on the distribution of observation sites (Valet et al., 1992; McFadden et al., 1993), relation with the configuration of the present field and paleosecular variation (Constable, 1992; Gubbins, 1994), and a link with a dynamo model (Gubbins and Sarson, 1994). Reliability of transitional records from sediments has, in particular, been suspected (Langereis et al., 1992; Van Hoof and Langereis, 1992; Prevot and Camps, 1993; Barton and McFadden, 1996). On other hand, it has been proposed that VGPs from volcanic rocks make clusters in a few geographical areas including Australia and the South Atlantic (Hoffman, 1992). Recent high-resolution transition records from sediment cores in the North Atlantic (Channell and Lehman, 1997; Mazaud and Channell, 1999) showed that VGP tracks are characterized by a stop-and-go feature with some hang-up points and that substantial smoothing by slower sedimentation rates results in the confined VGP paths. They provided a link between the preferred longitudinal bands from sediments and the VGP clusters from lavas, and suggested that sediments with high deposition rate may record changes in the geomagnetic field rather faithfully.

Rapid sedimentation, however, usually accompanies large 


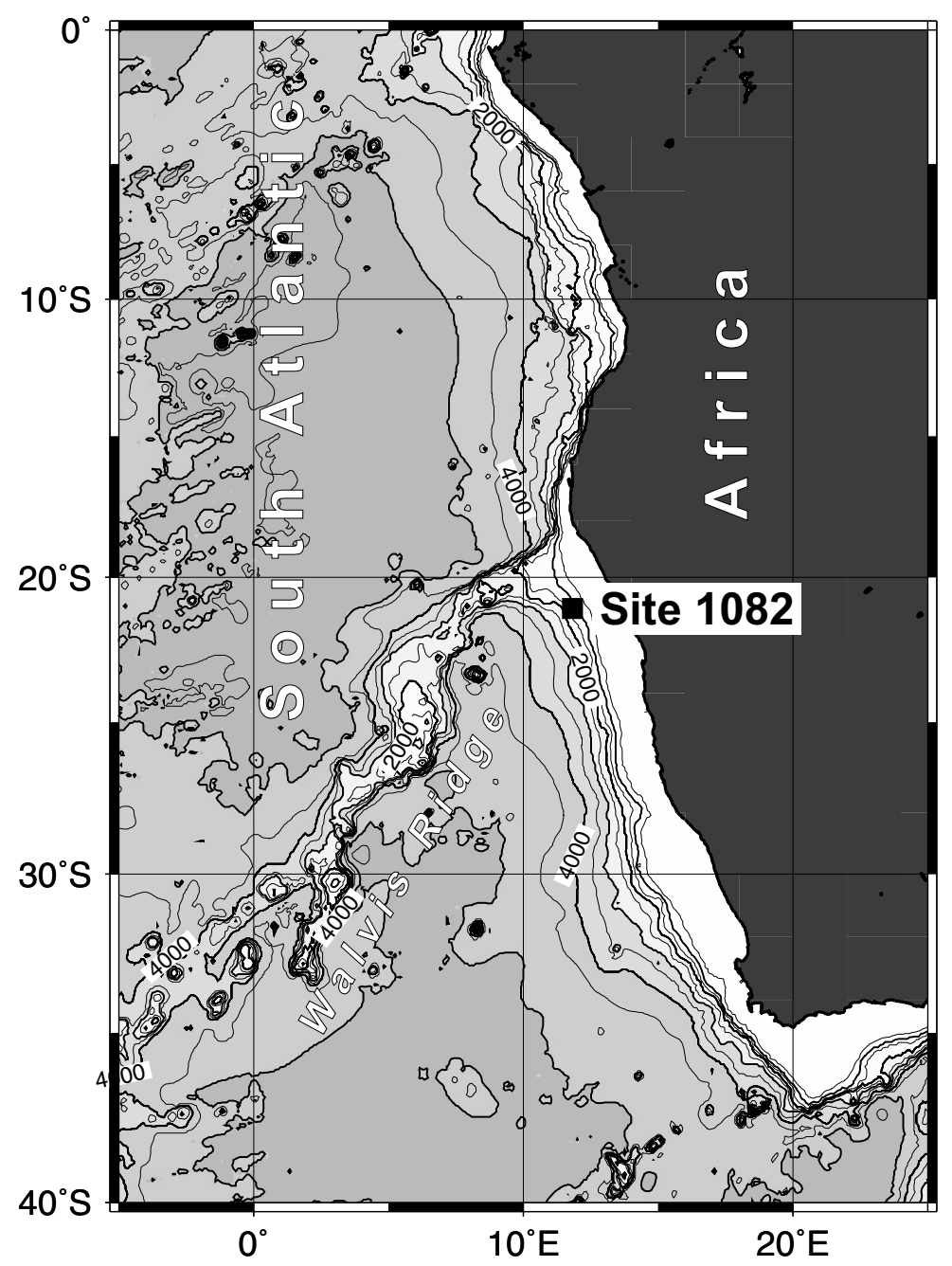

Fig. 1. Location of coring site. Bathymetric contours are at $500 \mathrm{~m}$ intervals.

supply of organic matter, which result in a reduced sedimentary environment. Such anoxic sediments have been considered to be unsuitable for paleomagnetic studies, because they are geochemically quite active and commonly suffer from secondary precipitation and/or dissolution of magnetic minerals. An exception is sediment drifts having low organic contents in spite of rapid sedimentation, from which high-quality polarity-transition records were reported (Channell and Lehman, 1997; Mazaud and Channell, 1999). Unfortunately, occurrence of sediment drifts is geographically very limited. Global and even distribution of paleomagnetic records is required for understanding the behavior of the geomagnetic field during a polarity transition, and thus paleomagnetists should make effort to derive reliable records from anoxic sediments.

We carried out a paleomagnetic study in order to obtain a record of the Brunhes-Matuyama $(\mathrm{B} / \mathrm{M})$ polarity transition from anoxic sediments of high deposition rate in the South Atlantic. The area is the least well covered region for the $\mathrm{B} / \mathrm{M}$ transition records (Love and Mazaud, 1997). We show the possibility that even anoxic sediments could preserve paleomagnetic signals, and discuss characteristics of the $\mathrm{B} / \mathrm{M}$ polarity transition.

\section{Materials}

We studied the $\mathrm{B} / \mathrm{M}$ polarity transition recorded in sediment cores from Hole $1082 \mathrm{C}\left(21^{\circ} 05.67^{\prime} \mathrm{S}, 11^{\circ} 49.23^{\prime} \mathrm{E}\right)$, which were taken during ODP Leg 175 (Fig. 1). The main purpose of the leg was to investigate the paleoceanography of the Angola-Benguela currents, and thirteen sites were occupied off the western coast of Africa between $5^{\circ}$ and $32^{\circ} \mathrm{S}$ (Wefer et al., 1998). Site 1082 is located in the Walvis Basin in a water depth of $1280 \mathrm{~m}$. Nannofossil- and foraminiferrich greenish clay was deposited during the late Pleistocene with an average sedimentation rate of about $100 \mathrm{~m} / \mathrm{m}$.y. (Shipboard Scientific Party, 1998). The B/M polarity boundary (0.78 Ma; Cande and Kent, 1992) occurs at about 80 meters composite depth (mcd). The high sedimentation rate of these cores is suitable for deriving a high resolution $\mathrm{B} / \mathrm{M}$ transition record. Total three holes were cored at Site 1082, but in Holes $1082 \mathrm{~A}$ and $1082 \mathrm{~B}$, the B/M transition was missing partly or completely because of core breaks. Precise age control of Site 1082 sediments was given by the oxygenisotope stratigraphy (John et al., personal communication). The result is consistent with the magnetostratigraphy, which will be discussed later.

The site lies close to the major upwelling center along the 
coast of southwest Africa, and the sediments have a high total-organic-carbon (TOC) content. The average at Site 1082 is about $5 \mathrm{wt} \%$, and sulfate reduction was completed within the top $20 \mathrm{~m}$ of the sediments (Murray et al., 1998). Sediments of high deposition rate have high organic carbon content in general, and such sediments are often thought to be unsuitable for paleomagnetic studies. We, however, consider we should not refuse Site 1082 sediments only because they are anoxic. In a moderately reduced environment, the oxic-anoxic boundary occurs in a sediment column within tens of centimeters to several meters from the top, which accompanies brown-to-green color change. In these sediments, dissolution and precipitation of magnetic minerals take place near the boundary (Karlin et al., 1987; Tarduno and Wilkison, 1996), and the secondary chemical remanent magnetization (CRM) may interfere or overcome the original detrital remanent magnetization (DRM). Such sediments cannot be used for paleomagnetic studies. In a strongly reduced environment like Site 1082, however, sediment column has quite thin or no oxidized layer at the top, and CRM could be interpreted as primary remanence even if it occurs because the lock-in depth of the CRM would be very small in this case. In the Site 1082 sediments, no color change indicative of the oxic-anoxic boundary was observed visually and in the spectrophotometry (Shipboard Scientific Party, 1998). We thus consider these sediments may preserve paleomagnetic field behavior.

Severe and rapid loss of remanent magnetization occurred during storage of the Site 1082 cores, with less than $10 \%$ of the initial intensity remaining a few months after core recovery (Yamazaki et al., 2000). The loss of magnetization was found commonly in the sediment cores taken during ODP Leg 175. A rock magnetic study of Yamazaki et al. (2000) indicated the presence of magnetite in the sediments even after the completion of sulfate reduction, and magnetization attributable to magnetite decreased with the loss of magnetization. It is hence considered that the transformation of magnetite into non-magnetic phases after core recovery is responsible for the loss of magnetization, although contribution of iron-sulfides like greigite is not clear. Comparison of onboard and onshore measurements indicated that directions of remanent magnetization did not change. Variations in remanent intensity after the loss of magnetization were almost parallel to the original variations. We consider that the original remanent directions are preserved even after the loss of magnetization, and thus these sediments could be used for a study on the $\mathrm{B} / \mathrm{M}$ transition.

\section{Measurements}

Each $1.5 \mathrm{~m}$ section of the Hole $1082 \mathrm{C}$ cores was sampled from the working half using U-channel samplers. The Uchannels are $1.5 \mathrm{~m}$ in length with a $2 \times 2 \mathrm{~cm}$ square cross section and a clip-on lid along one of the sides. Discrete samples of $7 \mathrm{~cm}^{3}$ were taken from the temporary archive half at 10 or $20 \mathrm{~cm}$ intervals between 76 and $84 \mathrm{mcd}$, which were already demagnetized by alternating field (AF) up to $20 \mathrm{mT}$ at half-core measurements onboard JOIDES Resolution.

Remanent magnetization of both U-channels and discrete samples was measured using a pass-through DC-SQUIDS magnetometer (2G Enterprises 760) with a standard $7.6 \mathrm{~cm}$ access at the Geological Survey of Japan (GSJ). The measurements of the U-channels were carried out at $0.5 \mathrm{~cm}$ intervals, but each data point is not independent because the half width of the response function of the pick-up coils is about $9 \mathrm{~cm}$. The GSJ magnetometer has an in-house designed sample-tray system with a magnetic moment on the order of $10^{-11} \mathrm{Am}^{2}$, which is significantly less magnetic than the one provided by the manufacturer of the magnetometer.

Remanent magnetization of the Site 1082 sediments, as well as other cores of ODP Leg 175 , was very weak, $10^{-3}$ to $10^{-5} \mathrm{~A} / \mathrm{m}$, which was an order of magnitude larger before the loss of magnetization (Yamazaki et al., 2000). Magnetic susceptibility of the Site 1082 sediments is dominated by paramagnetic materials. Progressive AF demagnetization of natural remanent magnetization (NRM) was carried out at peak fields of $20,25,30,35,40$, and $50 \mathrm{mT}$ for discrete samples (Fig. 2). Remanent directions were determined using the principal component analysis (PCA) (Kirschvink, 1980). Remanent magnetization after AF demagnetization of $20 \mathrm{mT}$ and higher consists of single component. Vector end-point diagrams, however, show relatively large scatter in the vicinity of the polarity reversal partly because the intensities were particularly low, an order of $10^{-5} \mathrm{~A} / \mathrm{m}$, which is close to that of the sample tray. The maximum angular deviation (MAD) of Kirschvink (1980) ranges from $10^{\circ}$ to $30^{\circ}$ for the samples from the interval between 79.2 and 81.6 mcd. The MADs outside this depth interval are less than $10^{\circ}$. A few samples with MADs larger than $30^{\circ}$ were rejected. Demagnetization paths of some samples go towards a point which is apart from the origin (Fig. 2). This is probably due to an error in correction for magnetization of the sample tray, but not the presence of a higher coercivity component.

Stepwise AF demagnetization of U-channel samples was carried out at peak fields of 5, 10, 15, 20, and $25 \mathrm{mT}$. A steep downward component acquired probably during coring was erased at AF of $10 \mathrm{mT}$. Remanent directions did not change significantly at demagnetization steps of $10 \mathrm{mT}$ and higher (Fig. 3), and we adopt directions after AF demagnetization of $20 \mathrm{mT}$ as characteristic directions. Resolution of U-channel remanent magnetization records can be enhanced by applying deconvolution (Oda and Shibuya, 1996, 1998). Because of the very low remanent intensities, however, signal-to-noise ratios of some intervals in Hole 1082C record were not high enough for obtaining reliable solutions in the deconvolution. All records presented in this paper are before deconvolution.

Remanent directions of discrete samples derived from PCA and those of U-channels after AF demagnetization of $20 \mathrm{mT}$ agree in general (Fig. 4). The consistency indicates that the magnetic overprint of a radial inward direction which has often been reported from ODP piston-cores and can cause erroneous polarity transition records (Herr et al., 1998 ) is negligibly small in general in the Hole 1082C sediments. An exception is that a swing of declination at about 79.9 mcd appeared only on the U-channel record. But only one discrete sample at 79.9 mcd corresponds to the interval of the swing, and its magnetization was particularly weak. 

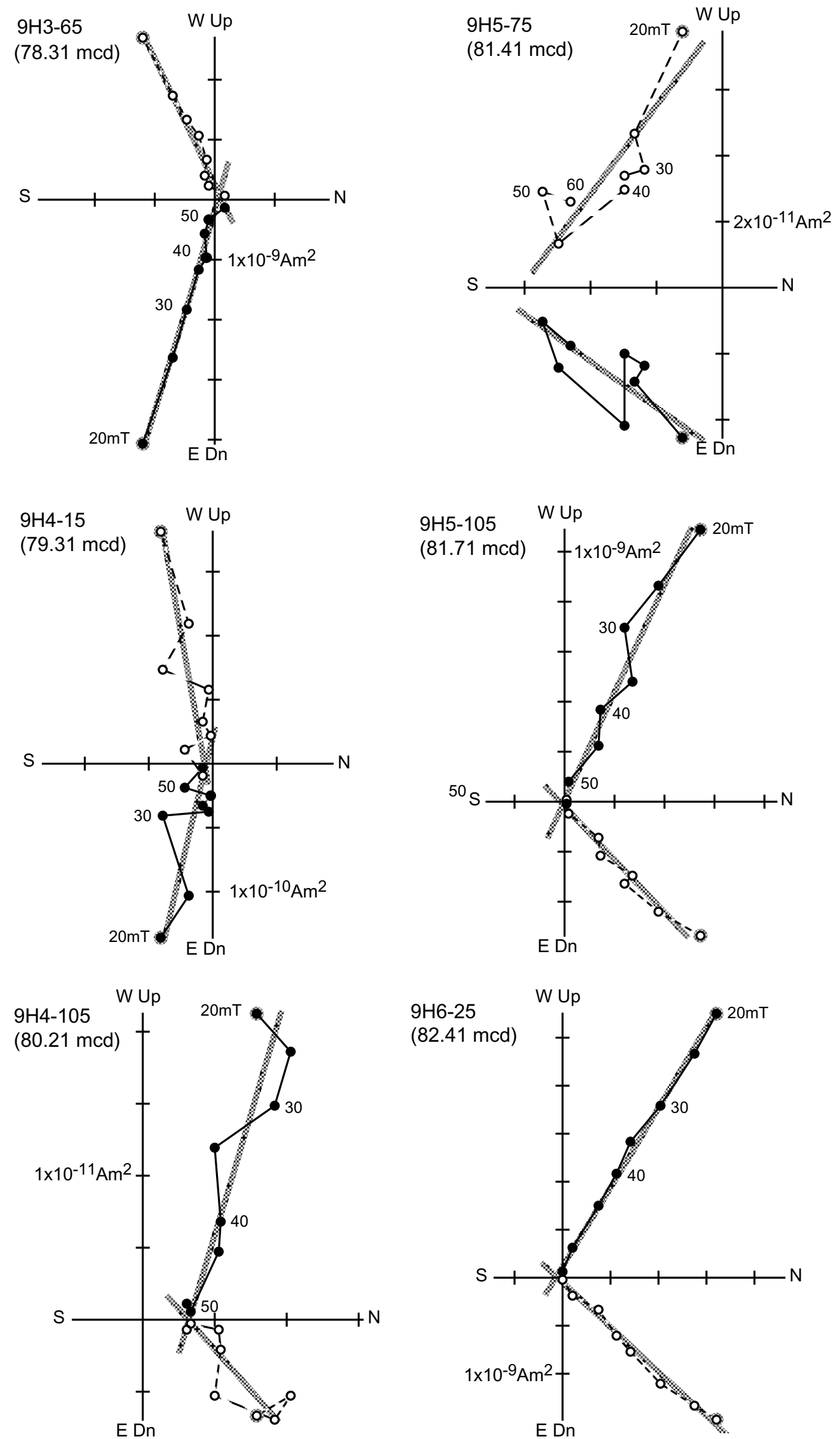

Fig. 2. Orthogonal plots of progressive alternating-field (AF) demagnetization on discrete samples from the temporary archive half of Hole 1082C cores. AF demagnetization of $20 \mathrm{mT}$ was applied at half-core measurement onboard JOIDES Resolution. Solid (open) circles are projection of vector endpoints on the horizontal (vertical) planes. Cores are not oriented azimuthally. 

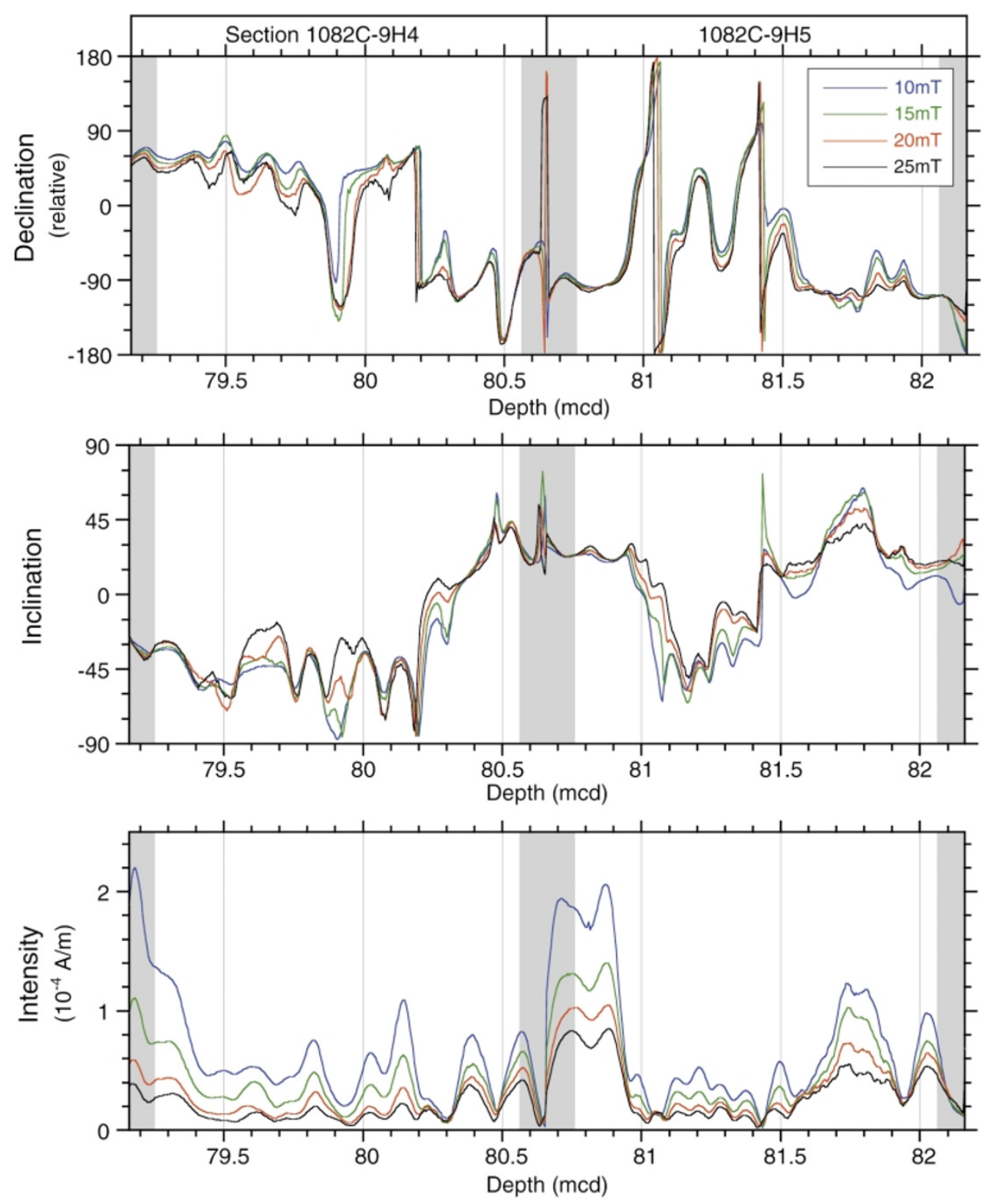

Fig. 3. Changes in remanent direction and intensity during stepwise AF demagnetization on U-channels from the working half of Hole $1082 \mathrm{C}$ cores. Top and bottom $10 \mathrm{~cm}$ of each section are shaded, where data were distorted by ends. Declinations are relative.

U-channels have a larger effective volume and thus higher signal-to-noise ratios at the measurement than discrete samples. We hence consider that the U-channel record is more reliable in these cores.

Experiments on artificial remanent magnetization acquisition were carried out to determine magnetic properties of the sediments, which is used to estimate relative paleointensity variations. Anhysteretic remanent magnetization (ARM) was given by superimposing a DC biasing field of $0.1 \mathrm{mT}$ on a smoothly decreasing alternating field with a peak of $80 \mathrm{mT}$. With a pulse magnetizer, isothermal remanent magnetization (IRM) of $0.3 \mathrm{~T}$ was imparted on a sample in the opposite direction after an IRM of $2.5 \mathrm{~T}$ was given, and $S$ ratios $\left(S_{-0.3 \mathrm{~T}}\right)$ were calculated according to the definition of Bloemendal et al. (1992). $S$ ratio indicates relative abundance of high-coercivity magnetic minerals such as hematite compared with low-coercivity minerals like magnetite, and higher $S$ ratio means higher proportion of low-coercivity minerals.

\section{Results}

\subsection{Direction of remanent magnetization}

Based on the remanent directions, the record shown in Fig. 4 can be divided into three intervals: the reversed polarity below $82 \mathrm{mcd}$, the transition zone between 79 and 82 mcd, and the normal polarity above 79 mcd. Remanent directions before and after the transition are almost antipodal. Relative declinations shifted about $180^{\circ}$. Inclinations outside the transition zone are close to those expected from the hypothetical geocentric axial dipole field $\left( \pm 37.5^{\circ}\right)$ at the site latitude $\left(21^{\circ} \mathrm{S}\right)$, although the inclinations after the transition are a little steeper than those before the transition. The slight difference is possibly due to non-dipole components or small magnetic overprint remained. 

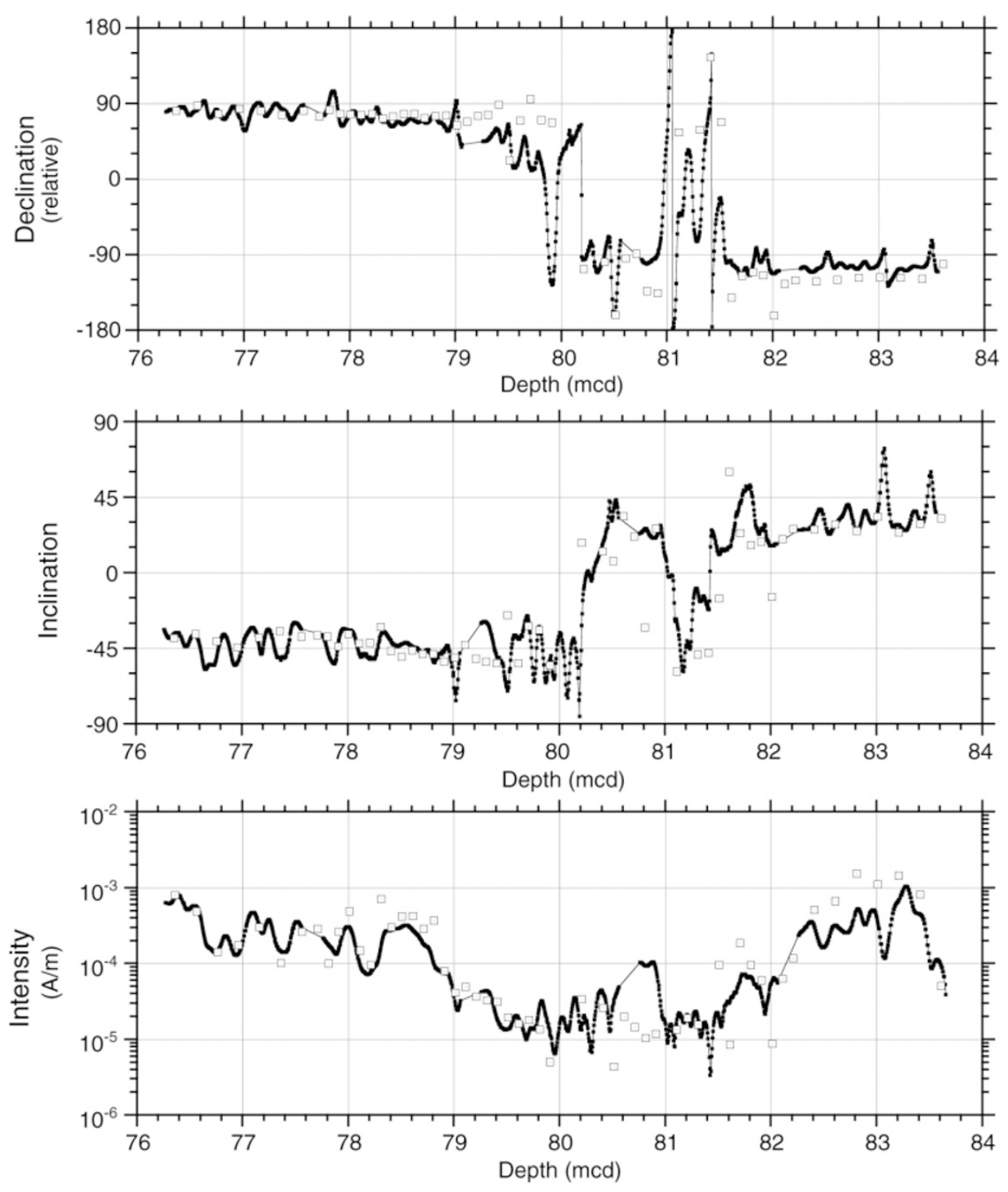

Fig. 4. Comparison of remanent magnetization on discrete samples from temporal archive halves of the cores (open squares) and U-channels from working halves (solids). Directions of discrete samples are based on the principal component analysis, while directions of U-channels and intensities of both are after AF demagnetization at $20 \mathrm{mT}$. Declinations are relative. The agreement between the two halves indicates that the radial-inward magnetic overprint often reported from ODP cores is negligibly small.

Rapid and large fluctuations of declinations took place between 81.0 and $81.5 \mathrm{mcd}$. Inclinations reached to a value of a full reversal. Then directions returned to the reversed polarity and settled again, which had lasted for about $0.8 \mathrm{~m}$. A shift from positive to negative inclinations with a flip of declination occurred at $80.2 \mathrm{mcd}$, which would correspond to the $\mathrm{B} / \mathrm{M}$ polarity boundary. Considering that each data point is not independent because of the smoothing by the measurement procedure, the shift should have been quite abrupt. Immediately after that, a swing-back of declination occurred between 79.8 and 80.0 mcd. Inclinations, however, showed a little steeper negative values at these depths rather than returning to the positive values.

\subsection{Normalized intensity}

Remanent magnetization intensities of discrete samples were normalized by ARM and saturation isothermal rema- nent magnetization (SIRM) (we regard the IRM acquired at 2.5T field as SIRM) (Fig. 5) to estimate relative paleointensity variations around the B/M boundary. Results of normalization by SIRM and ARM agree well. This indicates that magnetic grain-size change is not significant because the changes could result in variations in the ratio of ARM to SIRM. Concentration of magnetic minerals varies one order of magnitude or more, however, which was estimated from the acquisition of ARM and IRM (Fig. 5). The sediments of Hole $1082 \mathrm{C}$ thus did not fulfill the criteria of reliable relative paleointensity (Tauxe, 1993). The variations of ARM and IRM are inversely correlated with the total reflectance of the spectrophotometry (Fig. 5). In the Hole 1082A sediments during the Brunhes, total reflectance are positively correlated to calcium carbonate content (Shipboard Scientific Party, 1998); total reflectance of 30 to $50 \%$ corresponds 
(a)
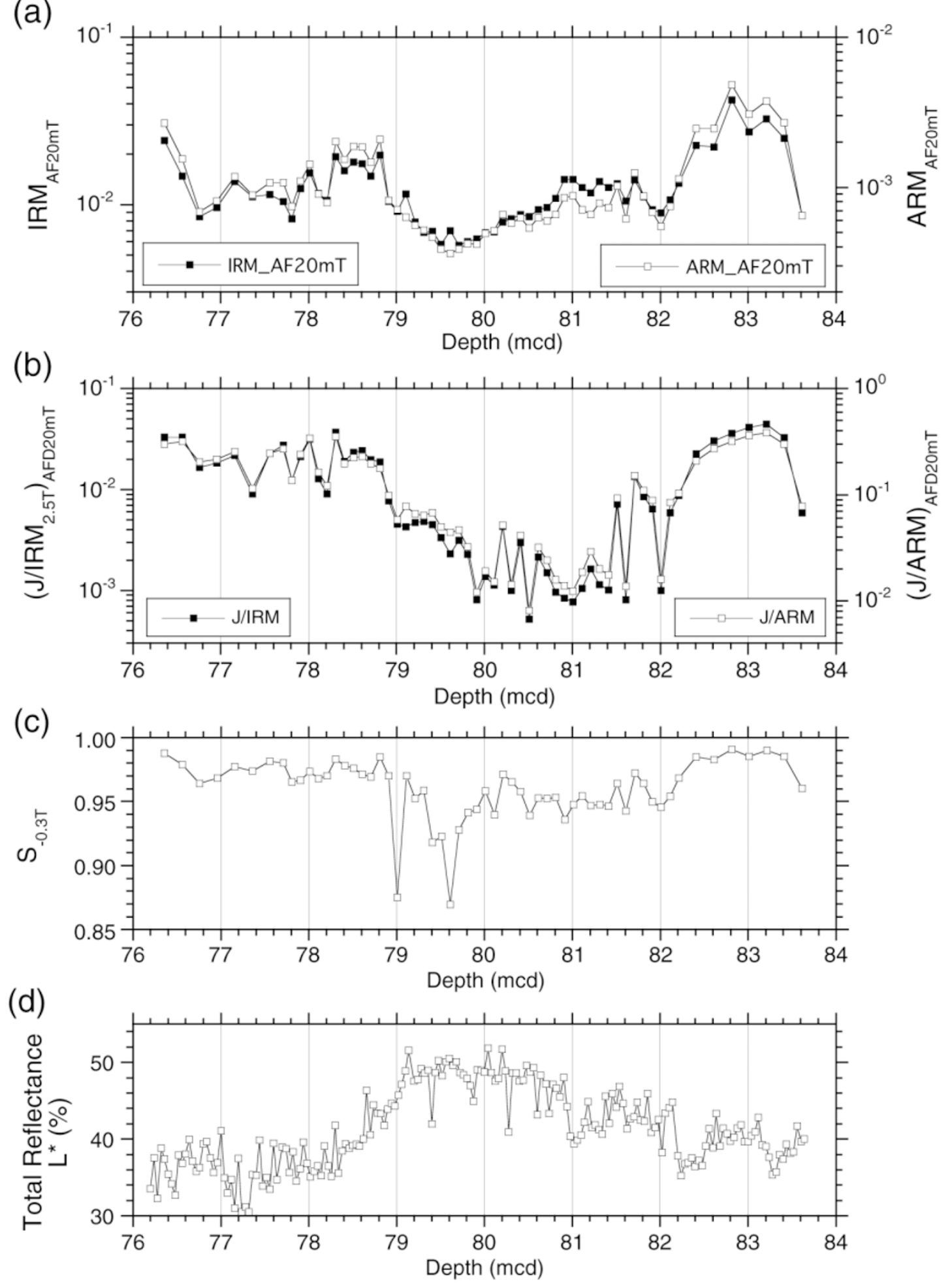

Fig. 5. (a) Remanent intensity normalized by ARM and IRM at 2.5T, which reflects first-order changes in relative paleointensity at the polarity transition, from discrete samples of Hole 1082C, (b) acquisition of ARM and IRM, (c) $S$ ratio $\left(S_{-0.3 \mathrm{~T}}\right)$, and (d) total reflectance ( $\left.L^{*}\right)$ of spectrophotometry. Calcium carbonate contents are positively correlated to $L^{*}$ in Hole 1082A sediments (Shipboard Scientific Party, 1998).

to calcium carbonate of about 10 to $70 \%$. The negative correlation of IRM and ARM with total reflectance suggests that dilution by the carbonate component is responsible for their variations.

Some changes in composition of magnetic minerals are suggested from $S$ ratios. $S$ ratios between 79 and $82 \mathrm{mcd}$ are somewhat lower than those outside this depth interval, indicating that the proportion of high-coercivity magnetic minerals increased with the decrease in concentration of magnetic minerals (Fig. 5). Even in the low $S$ ratio interval, remanent magnetization is dominated by low-coercivity minerals, probably magnetite, and thus the $S$ ratio variations 
would not considerably alter relative paleointensity estimation.

The loss of remanent intensity after core recovery may also have affected the normalized intensity. We consider that relative paleointensity information has still been preserved in the sediments because NRM intensity variations before and after the loss of magnetization were almost parallel (Yamazaki et al., 2000), and that dissolution of magnetic minerals destroys both NRM intensity and the normalizers, ARM and SIRM. The dissolution can cause magnetic grainsize changes (Yamazaki et al., 2000), which would affect both ARM and IRM but in a different way. But the similarity of the records normalized by ARM and IRM suggests that the effect in relative paleointensity estimation was small if any. In summary, the sediments of Hole 1082C showed some rock-magnetic inhomogeneity, and are not ideal for relative paleointensity determination. However, we consider it is still possible to derive first-order variations in relative paleointensity, and regard the normalized intensity as relative paleointensity.

Decrease in relative paleointensity at the $\mathrm{B} / \mathrm{M}$ transition started somewhat earlier than directional changes (Figs. 4 and 5). The intensities during the transition were 5 to $10 \%$ of those before and after the transition. Intensity minima occurred at about 80.0 and $81.0 \mathrm{mcd}$, which correspond to the main polarity reversal and the fluctuation before that, respectively. The intensity showed some recovery between the two minima. Between 79.0 and 79.8 mcd after the second minima, the intensity remained at an intermediate strength between that at the minima and after full recovery. Intensities after full recovery did not differ significantly from those before the transition.

\section{Discussion}

We have attempted to recover a $\mathrm{B} / \mathrm{M}$ polarity transition record from Hole 1082C. The measurements, however, proved some problems in reliability of the record. The anoxic sediments showed extremely low magnetization intensity and rather noisy demagnetization diagrams. They also have some rock-magnetic inhomogeneity. Mechanism of remanent magnetization acquisition is ambiguous; possibly CRM. We, however, discuss here that our record displays features similar to the characteristics of the B/M polarity transition reported by previous studies, and suggest the possibility that anoxic sediments could be used for studies on polarity transitions.

\section{1 "Precursor" of the $\mathrm{B} / \mathrm{M}$ transition}

The B/M polarity transition record from Hole $1082 \mathrm{C}$ revealed a zone of large directional fluctuations with low intensities about $1 \mathrm{~m}$ below the main transition. The occurrence of double paleointensity drops at the $\mathrm{B} / \mathrm{M}$ transition has already been reported by Kent and Schneider (1995) and Hartl and Tauxe (1996). The reversal occurred at the second minimum, and the earlier one, called "precursor" by Hartl and Tauxe (1996), is considered to have caused by geomagnetic field instability just before the transition. The "precursor" is estimated to have occurred ca. 15 kyrs before the main transition. Some previous "precursor" records accompany directional excursions, but others show only intensity drops (Hartl and Tauxe, 1996). This discrepancy is probably due to the difference in resolution depending on sedimentation rates. The directional excursion could be caused by viscous remanent magnetization (VRM) of Brunhes age, but we estimate that the VRM is not significant in our records because of the similar normalized intensity before and after the $\mathrm{B} / \mathrm{M}$ transition.

Precise age-control of the polarity transition record from Hole $1082 \mathrm{C}$ was achieved by the oxygen-isotope stratigraphy. Oxygen-isotope ratios $\left(\delta^{18} \mathrm{O}\right)$ were measured on Hole 1082A cores (John et al., personal communication), and transferred to Hole $1082 \mathrm{C}$ using the composite depth (Fig. 6). Interpretation of the $\delta^{18} \mathrm{O}$ record is not straightforward, partly because of a core-break between 81.4 to 83.0 mcd at Hole 1082A. If we assign $\delta^{18} \mathrm{O}$ stage 18.4 (754 $\mathrm{ka}$, Bassinot et al., 1994) to a minimum at $77.5 \mathrm{mcd}$, and stage $20.2(793 \mathrm{ka})$ to a drop at $81.4 \mathrm{mcd}$, the average sedimentation rate between the two control points becomes 10.0 $\mathrm{cm} / \mathrm{kyr}$, which is almost the same as the average during the Brunhes Chron, $10.3 \mathrm{~cm} / \mathrm{kyr}$. Assuming a depth lag of $2 \mathrm{~cm}$ for the post-depositional remanent magnetization (pDRM) acquisition (Tauxe et al., 1996) (or chemical lock-in depth of $2 \mathrm{~cm}$ ), the main transition at $80.2 \mathrm{mcd}$ is dated as 781 $\mathrm{ka}$, and the fluctuation from 80.9 and $81.6 \mathrm{mcd}$ is from 788 to $795 \mathrm{ka}$. The occurrence of the fluctuation correlative to the "precursor" at the horizon close to the expected age suggests that the anoxic sediments we studied have preserved the variations of the geomagnetic field. The agreement of the age of the main transition with the known age for $\mathrm{B} / \mathrm{M}$ boundary supports the idea that the lock-in depth of the remanent magnetization of this sediments is small enough to be interpreted as primary even if it is of CRM origin.

\subsection{VGP positions}

We calculated VGP positions (Figs. 6 and 7) from characteristic directions of the remanent magnetization on $U$ channels (Fig. 4). Orientation of the cores was performed by rotating the mean declination of U-channels after the completion of the polarity transition from 76 to $78 \mathrm{mcd}$ to the north. Then, we compare the features of our record with the previous records to see whether they have similarities.

VGP paths at the precursor between 81 and $81.5 \mathrm{mcd}$ passed two longitudinal bands; one was between $90^{\circ}$ and $120^{\circ} \mathrm{E}$, and the other between $60^{\circ}$ and $120^{\circ} \mathrm{W}$ (Fig. 7). VGPs of the reversed-to-normal transition at $80.2 \mathrm{mcd}$ tracked northward over the central Pacific rapidly. Immediately after that, a large swing of VGPs occurred from the North America to the east of Australia. This corresponds to directional changes on U-channels between 79.8 and $80.0 \mathrm{mcd}$, but was not detected by discrete samples. Between 79.2 and 79.8 mod after the swing, VGPs stayed in the middle to high latitudes of the northern hemisphere, at about $30^{\circ}$ to $60^{\circ} \mathrm{N}$ over the North America. However, the VGP positions in this interval may not be reliable because of the discrepancy of about $40^{\circ}$ in declination between U-channels and discrete samples. VGPs finally moved to the vicinity of the north pole at about $79 \mathrm{mcd}$ and settled there.

The VGP paths at the precursor lie close to the so-called preferred longitudinal bands (Clement, 1991; Laj et al., 1991), and are about $\pm 90^{\circ}$ from the longitude of the observation site $\left(11^{\circ} \mathrm{E}\right)$. The reliability of sediments to record directional changes during polarity transitions remains highly 

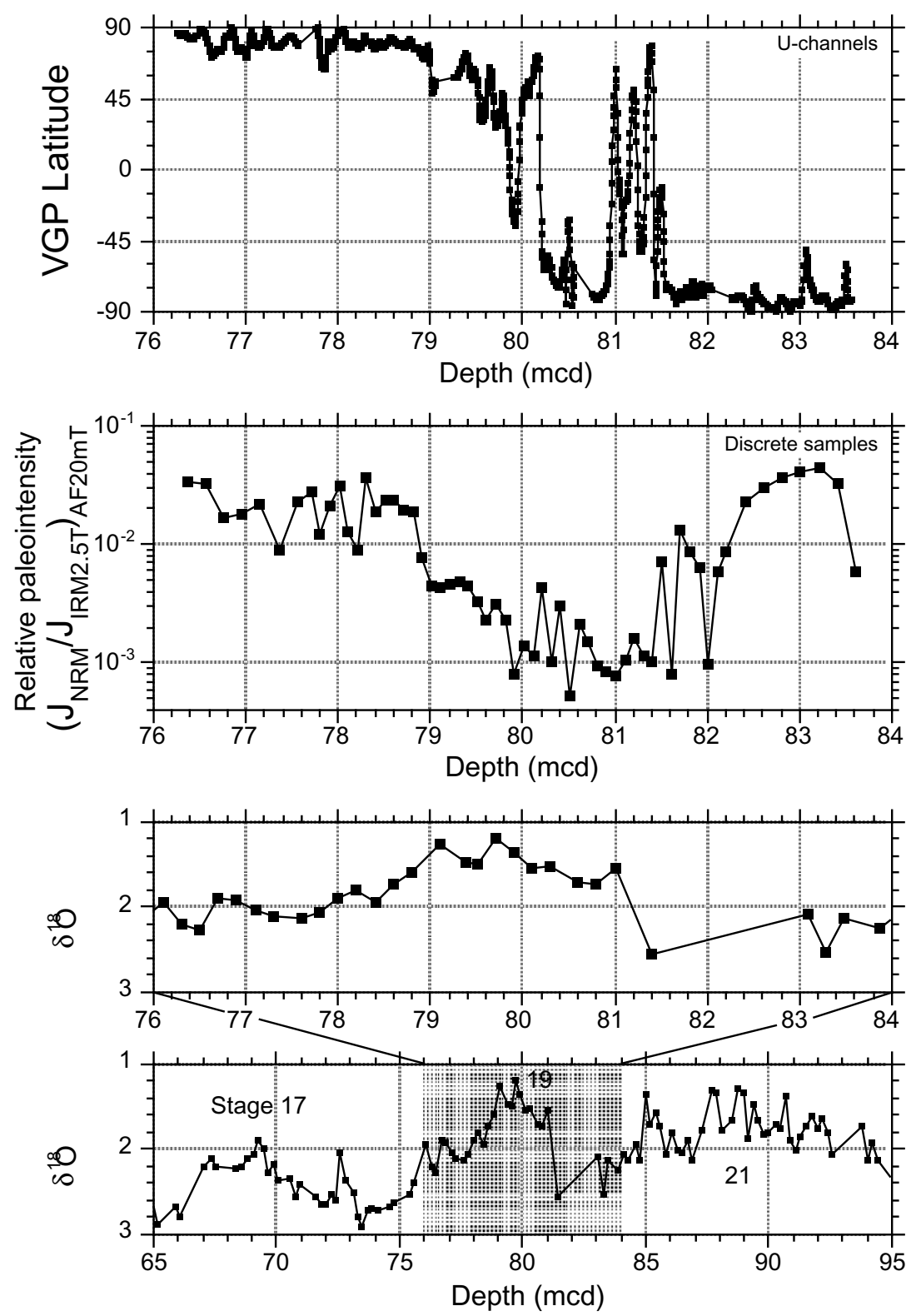

Fig. 6. Variation of VGP latitude at Brunhes-Matuyama transition from Hole $1082 \mathrm{C}$ cores based on U-channel samples (top), relative paleointensity from discrete samples (middle), and oxygen-isotope ratio $\left(\delta^{18} \mathrm{O}\right)$ after John et al., personal communication (bottom). Between 79.0 and $79.8 \mathrm{mcd}$, relative paleointensity remained at an intermediate strength between that at the minima and after full recovery with middle-to-high VGP latitudes.

controversial (e.g., Langereis et al., 1992; Quidelleur et al., 1995). In particular, Barton and McFadden (1996) showed that the confinement of VGPs $90^{\circ}$ away from their site longitudes occurs if extreme inclination shallowing happens under low geomagnetic-field intensities during polarity transitions. In our record, VGPs at the main transition and the swing after it do not follow the two longitudinal bands, although relative paleointensities at these intervals are as low as those at the precursor. We thus consider that the inclination shallowing would not be serious unless magnetic properties of the sediments including grain size and shape differ significantly at the precursor interval and more susceptible to inclination shallowing than other intervals, and we do not have any evidence for such magnetic property changes.

Oda et al. (2000) suggested based on the $\mathrm{B} / \mathrm{M}$ transition records of ODP Leg 124 sediments and some other records that after the main transition VGPs temporarily stayed in the middle to high latitudes over the North America for about 4000 years with an intermediate field intensity and then moved to the north pole with full recovery of the intensity. The Hole 1082C record just after transition has similar feature. Relative intensity between 79.0 and $79.8 \mathrm{mcd}$ showed an intermediate strength between that at the transition and after full recovery (Fig. 6). The VGPs of this interval also stayed over the North America (Fig. 7), although these positions our record may not be reliable. The duration of the intermediate intensity was about 5000 years. There is a possibility that the geodynamo has a meta-stable state with a field configuration close to a dipole. Further investigations are needed to know if the meta-stable state occurs in other reversals.

Based on the average sedimentation rate of $10 \mathrm{~cm} / \mathrm{kyr}$, a 

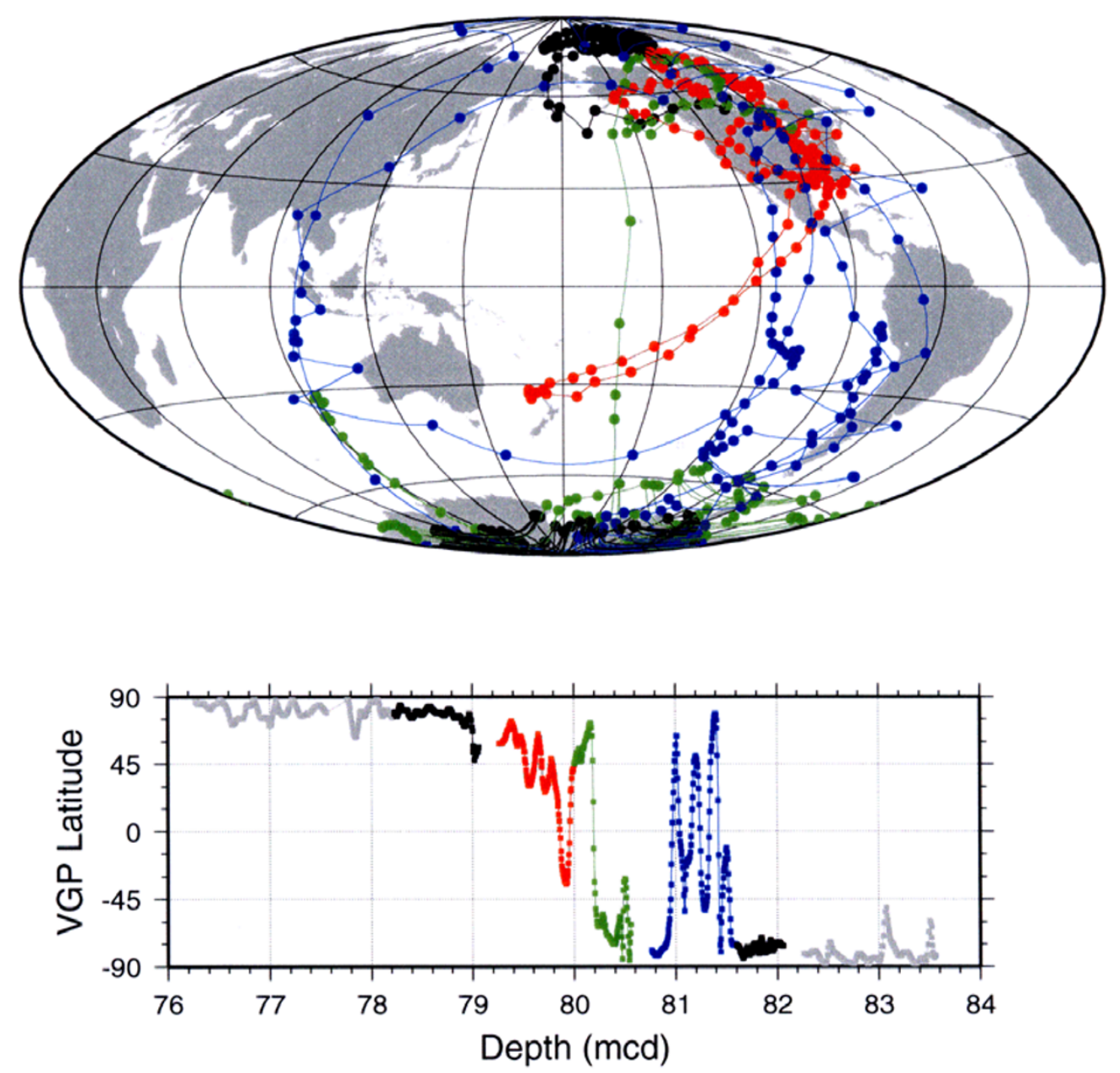

Fig. 7. Geographical movement of virtual geomagnetic pole (VGP) positions during Brunhes-Matuyama transition (top), and variation of VGP latitudes with depth of the cores from Hole 1082C (bottom). VGPs from 82.1 to 78.2 mcd were plotted. VGPs around the main transitions are presented in green, whereas fluctuations before and after the main transitions are shown in blue and red, respectively.

period of time required for each of the two VGP loops in our "precursor" record was estimated to be about 2 kyrs, which is similar to the period of the westward drift of non-dipole components (Yukutake and Tachinaka, 1969). The swing of VGPs about 2 kyrs after the main transition also took about 2 kyrs. It is thus estimated that these fluctuations would be manifestation of the drifting non-dipole components which would have dominated the geomagnetic field when the axial dipole field was weak.

\section{Conclusions}

We have conducted a paleomagnetic study of the Hole $1082 \mathrm{C}$ sediment cores in order to obtain a $\mathrm{B} / \mathrm{M}$ polarity transition record. The cores consists of strongly anoxic sediments, and their remanent magnetization may be of CRM, which were considered to be unsuitable for polarity-transition studies in general. Our record has, however, showed following features similar to the characteristics of the $B / M$ polarity transition reported by previous studies.

(1) A zone of large directional fluctuations with low paleointensities has been found at about $1 \mathrm{~m}$ below the main transition, which would correspond to the "precursor" of Hartl and Tauxe (1996). The age of the fluctuation inter- val based on $\delta^{18} \mathrm{O}$ stratigraphy, 788 to $795 \mathrm{ka}$, is close to the known one: ca. 15 kyrs before the main transition.

(2) VGPs at the precursor lie along the so-called preferred longitudinal bands over the north-south Americas and Australia-east Asia.

(3) After the main transition from the reversed-to-normal polarity, VGPs stay in the middle-to-high latitudes over the North America with an intermediate paleointensity for about 5 kyrs, and then move in the vicinity of the North Pole with full recovery of intensity. Similar behavior was reported by Oda et al. (2000).

Fluctuations of VGPs seem to have a time constant similar to the non-dipole field. A period of 2 kyrs was estimated for each of the two VGP loops in our "precursor" record. A large swing of VGPs for about 2 kyrs occurred immediately after the main transition ( $\sim 2 \mathrm{kyrs})$. These fluctuations would be manifestation of the drifting non-dipole components which would have dominated the geomagnetic field when the axial dipole field was weak.

These facts suggest the possibility that anoxic sediments could record the geomagnetic field behavior.

Acknowledgments. We thank Gina Frost and Peter Solheid for the help of measurement onboard JOIDES Resolution, Barbara 
Donner for providing the unpublished oxygen-isotope data, and Carl Richter for discussion. We also thank Koji Fukuma, an anonymous reviewer, and the journal editor Hidetoshi Shibuya for valuable comments. T. Y. thanks Ocean Research Institute, University of Tokyo for the support to participate in ODP Leg 175. Part of this study was supported by the Superplume Project of the Science and Technology Agency.

\section{References}

Barton, C. E. and P. L. McFadden, Inclination shallowing and preferred transitional VGP paths, Earth Planet. Sci. Lett., 140, 147-157, 1996.

Bassinot, F. C., L. D. Labeyrie, E. Vincent, X. Quidelleur, N. J. Shackleton, and Y. Lancelot, The astronomical theory of climate and the age of the Brunhes-Matuyama magnetic reversal, Earth Planet. Sci. Lett., 126, 91$108,1994$.

Bloemendal, J., J. W. King, F. R. Hall, and S.-J. Doh, Rock magnetism of Late Neogene and Pleistocene deep-sea sediments: relationship to sediment source, diagenetic processes, and sediment lithology, J. Geophys. Res., 97, 4361-4375, 1992

Cande, S. C. and D. V. Kent, A new geomagnetic polarity time scale for the Late Cretaceous and Cenozoic, J. Geophys. Res., 97, 13917-13951, 1992.

Channell, J. E. T. and B. Lehman, The last two geomagnetic polarity reversals recorded in high-deposition-rate sediment drifts, Nature, 389, 712$715,1997$.

Clement, B. M., Geographical distribution of transitional VGPs: evidence for non-zonal equatorial symmetry during the Matuyama-Brunhes geomagnetic reversal, Earth Planet. Sci. Lett., 104, 48-58, 1991.

Constable, C., Link between geomagnetic reversal paths and secular variation of the field over the past 5 Myr, Nature, 358, 230-233, 1992.

Glatzmaier, G. A. and P. H. Roberts, A three-dimensional self-consistent computer simulation of a geomagnetic field reversal, Nature, 377, 203$209,1995$.

Gubbins, D., Geomagnetic polarity reversals: a connection with secular variation and core-mantle interaction?, Rev. Geophys., 32, 61-83, 1994.

Gubbins, D. and G. Sarson, Geomagnetic field morphologies from a kinematic dynamo model, Nature, 368, 51-55, 1994.

Hartl, P. and L. Tauxe, Precursor to the Matuyama/Brunhes transition-field instability as recorded in pelagic sediments, Earth Planet. Sci. Lett., 138, 121-135, 1996.

Herr, B., M. Fuller, M. Haag, and F. Heider, Influence of drilling on two records of the Matuyama/Brunhes polarity transition in marine sediment cores near Gran Canaria, in Proc. ODP Sci. Results., 157, edited by $\mathrm{P}$ P. E. Weaver, H.-U. Schmincke, J. V. Firth, and W. Duffield, pp. 57-69, Ocean Drilling Program, College Station, 1998.

Hoffman, K. A., Dipolar reversal states of the geomagnetic field and coremantle dynamics, Nature, 359, 789-794, 1992.

Karlin, R., M. Lyle, and G. R. Heath, Authigenic magnetite formation in suboxic marine sediments, Nature, 326, 490-493, 1987.

Kent, D. V. and D. A. Schneider, Correlation of paleointensity variation recorded in the Brunhes/Matuyama polarity transition interval, Earth Planet. Sci. Lett., 129, 135-144, 1995.

Kirschvink, J. L., The least-squares line and plane and the analysis of palaeomagnetic data, Geophys. J. R. astr. Soc., 62, 699-718, 1980.

Laj, C., A. Mazaud, R. Weeks, M. Fuller, and E. Herrero-Bervera, Geomagnetic reversal paths, Nature, 351, 447, 1991.

Langereis, C. G., A. A. M. van Hoof, and P. Rochette, Longitudinal confinement of geomagnetic reversal paths as a possible sedimentary artefact, Nature, 358, 226, 230, 1992.
Love, J. J. and A. Mazaud, A database for the Matuyama-Brunhes magnetic reversal, Phys. Earth Planet. Inter., 103, 207-245, 1997.

Mazaud, A. and J. E. T. Channell. The top Olduvai polarity transition at ODP Site 983 (Iceland Basin), Earth Planet. Sci. Lett., 166, 1-13, 1999.

McFadden, P. L., C. E. Barton, and R. T. Merrill, Do virtual geomagnetic poles follow preferred paths during geomagnetic reversals?, Nature, 361, 342-344, 1993.

Murray, R. W., R. Wigley, and Shipboard Scientific Party, Interstitial water chemistry of deeply buried sediments from the southwest African margin: a preliminary synthesis of results from Leg 175, in Proc. ODP Init. Repts., 175, edited by G. Wefer, W. H. Berger, and C. Richter et al. pp. 547-553, Ocean Drilling Program, College Station, 1998.

Oda, H. and H. Shibuya, Deconvolution of long-core paleomagnetic data of Ocean Drilling Program by Akaike's Bayesian Information Criterion minimization, J. Geophys. Res., 101, 2815-2834, 1996.

Oda, H. and H. Shibuya, An improvement in ABIC-minimizing deconvolution for continuously measured magnetic remanence data, Earth Planets Space, 50, 15-22, 1998.

Oda, H., H. Shibuya, and V. Hsu, High resolution paleomagnetic records of Brunhes/Matuyama polarity transition from ODP Leg 124 (Celebes and Sulu Seas), Geophys. J. Int., 142, 319-338, 2000.

Prevot, M. and P. Camps, Absence of preferred longitude sectors for poles from volcanic records of geomagnetic reversals, Nature, 366, 53-57, 1993.

Quidelleur, X., J. Holt, and J.-P. Valet, Confounding influence of magnetic fabric on sedimentary records of a field reversal, Nature, 374, 246-249, 1995.

Shipboard Scientific Party, Site 1082, in Proc. ODP Init. Repts., 175, edited by G. Wefer, W. H. Berger, and C. Richter et al., pp. 273-312, Ocean Drilling Program, College Station, 1998.

Tarduno, J. A. and S. L. Wilkison, Non-steady state magnetic mineral reduction, chemical lock-on, and delayed remanence acquisition in pelagic sediments, Earth Planet. Sci. Lett., 144, 315-326, 1996.

Tauxe, L., Sedimentary records of relative paleointensity of the geomagnetic field: Theory and practice, Rev. Geophys., 31, 319-354, 1993.

Tauxe, L., T. Herbert, N. J. Shackleton, and Y. S. Kok, Astronomical calibration of the Matuyama-Brunhes boundary: consequences for magnetic remanence acquisition in marine carbonates and the Asian loess sequence, Earth Planet. Sci. Lett., 140, 133-146, 1996.

Valet, J.-P., P. Tucholka, V. Courtillot, and L. Meynadier, Paleomagnetic constraints on the geometry of the geomagnetic field during reversals, Nature, 356, 400-407, 1992.

Van Hoof, A. A. M. and C. G. Langereis, The upper and lower Thvera sedimentary geomagnetic reversal records from southern Sicily, Earth Planet. Sci. Lett., 114, 59-75, 1992.

Wefer, G., W. H. Berger, and C. Richter, et al., Proceedings of the Ocean Drilling Program, Initial Reports, 175 (Part 1), 577 pp., Ocean Drilling Program, College Station, 1998.

Yamazaki, T., P. A. Solheid, and G. M. Frost, Rock magnetism of sediments in the Angola-Namibia upwelling system with special reference to loss of magnetization after core recovery, Earth Planets Space, 52, 329-336, 2000.

Yukutake, T. and H. Tachinaka, Separation of the Earth's magnetic field into the drifting and the standing parts, Bull. Earthq. Res. Inst., 47, 6597, 1969.

T. Yamazaki (e-mail: toshi-yamazaki@aist.go.jp) and H. Oda 